\title{
Highly active water-soluble palladium catalyst for the regioselective carbonylation of vinyl aromatics to 2 -arylpropionic acids
}

\author{
S. Jayasree, A. Seayad and R. V. Chaudhari* \\ Homogeneous Catalysis Division, National Chemical Laboratory, Pune-411 008, India. E-mail: rvc@ems.ncl.res.in
}

\author{
Received (in Cambridge, UK) 12th April 2000, Accepted 30th May 2000 \\ Published on the Web 20th June 2000
}

A novel water-soluble Pd complex containing pyridine carboxylate and TPPTS as ligands is a highly active catalyst for the carbonylation of vinyl aromatics under biphasic conditions and provides high regioselectivity to 2 -arylpropionic acids.

Biphasic catalytic reactions using water-soluble transition metal complexes are of much current interest since they provide the unique advantages of homogeneous catalysis as well as facilitating the easy separation of the catalyst from the products. ${ }^{1}$ While biphasic hydroformylation of olefins using water-soluble $\mathrm{Rh}$ catalysts has been practiced industrially, ${ }^{2}$ the biphasic hydrocarboxylation of olefins is still at an exploratory stage, mainly due to the low catalytic activity and selectivity offered by most of the catalyst systems studied so far. An important application of hydrocarboxylation is in the synthesis of 2-arylpropionic acids, a class of non-steroidal anti-inflammatory agents, from the corresponding vinyl aromatic compounds ${ }^{3}$ or aryl ethanols. ${ }^{4}$ Biphasic carbonylation using in situ prepared $\operatorname{Pd}(\mathrm{TPPTS})_{3}$ catalyst along with acidic promoters provided only very low catalytic activity $\left(\mathrm{TOF}=1.5-50 \mathrm{~h}^{-1}\right)$ and 2-arylpropionic acid selectivity (50-70\%) under mild reaction conditions of $60-120{ }^{\circ} \mathrm{C}$ and $40-60$ bar. $^{5} \mathrm{~A}$ maximum regioselectivity of $90.2 \%$ was reported at higher $\mathrm{CO}$ pressure (140 bar), but with very low catalytic activity $\left(\mathrm{TOF}=5 \mathrm{~h}^{-1}\right) .5 a$ Cationic water-soluble $\mathrm{Pd}$ complexes containing bidentate diphosphine 2,7-bis $\left(\mathrm{SO}_{3} \mathrm{Na}\right)$-Xantphos was reported recently to catalyse the hydrocarboxylation of olefins, which also provided low catalytic activity (TOF $=5 \mathrm{~h}^{-1}$ ) and 2-arylpropionic acid $(35 \%)$ selectivity. ${ }^{6}$ Here we report for the first time a novel water-soluble Pd catalyst system for the biphasic carbonylation of vinyl aromatic compounds, which provides significantly improved turnovers and 2-arylpropionic acid regioselectivity.

Recently, we have reported a novel PdII complex containing pyridine carboxylate, $\mathrm{PPh}_{3}$ and $\mathrm{TsO}^{-}$ligands (I), which was found to be an efficient carbonylation catalyst under homogeneous conditions. ${ }^{7}$ Here, we demonstrate that a novel watersoluble Pd catalyst prepared $\dagger$ by exchanging the $\mathrm{PPh}_{3}$ ligand of complex I with TPPTS [tris $(m$-sulfophenyl $)$ phosphine trisodium salt] (Scheme 1), is a highly active catalyst for the carbonylation of vinyl aromatics under biphasic conditions (Scheme 2). For instance, in the case of carbonylation of styrene, high catalytic activities (TOF) up to $550 \mathrm{~h}^{-1}$ (ca.10 times higher than the previously reported catalyst systems) were achieved with high regioselectivity to $\mathrm{CH}_{3} \mathrm{CHPhCO}_{2} \mathrm{H}$ (up to $95 \%$ ) at lower $\mathrm{CO}$ pressure (54 bar). The catalyst system $\mathrm{PdCl}_{2}-$ 4TPPTS gave only a very low reaction rate $\left(\mathrm{TOF}=34 \mathrm{~h}^{-1}\right)$ and $\mathrm{CH}_{3} \mathrm{CHPhCO}_{2} \mathrm{H}$ selectivity $(41 \%)$ under the present set of conditions. In a typical carbonylation experiment, $\neq$ the aqueous catalyst, $\mathrm{LiCl}$, TsOH and the substrate dissolved in toluene were

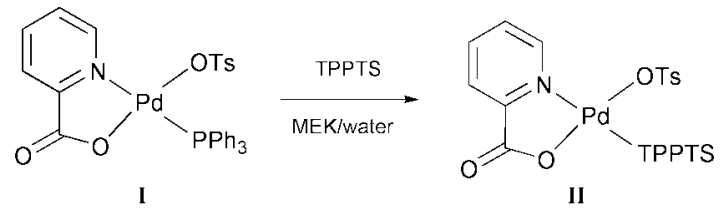

Scheme 1 Synthesis of water-soluble Pd complex II. charged to a stirred pressure reactor and the reaction was carried out at 54 bar of $\mathrm{CO}$ partial pressure at $115^{\circ} \mathrm{C}$ under $1100 \mathrm{rpm}$ for a specified time. The reaction mixture was analyzed by GC $\S$ and the products were confirmed by GC-MS and NMR.

An attempt was made to characterize the water-soluble $\mathrm{Pd}$ complex formed after the exchange of $\mathrm{PPh}_{3}$ with TPPTS, by isolation from $\mathrm{H}_{2} \mathrm{O}$ by precipitation using EtOHI.If The pale yellow complex obtained was stable in the solid state and in solution under Ar but its aqueous solution gradually decomposed to a red solution within 2-3 days on exposure to air. IR of the isolated complex showed $\mathrm{C}=\mathrm{O}$ stretching vibrations at 1636 $\mathrm{cm}^{-1}$ and $\mathrm{Pd}-\mathrm{N}$ vibrations at $524 \mathrm{~cm}^{-1}$. ${ }^{31} \mathrm{P}$ NMR in $\mathrm{D}_{2} \mathrm{O}$ showed a strong signal at $35.31 \mathrm{ppm}$ and a weak signal at 36.13 ppm, which may be due to the trans ( $\mathrm{N}$ trans to TPPTS) and cis (N cis to TPPTS) isomers respectively. ${ }^{1} \mathrm{H}$ NMR and elemental analysis were consistent with the structure of II given in Scheme 1.\|

The typical results of carbonylation of styrene are presented in Table 1. The best catalytic activity and selectivity was achieved with 2 equiv. of TPPTS to Pd, unlike the classical $\mathrm{PdCl}_{2}$-TPPTS system where 4-6 equiv. TPPTS to Pd were required to obtain the highest catalytic activity. Further increase in TPPTS concentration lowered the catalytic activity as well as the $\mathrm{CH}_{3} \mathrm{CHPhCO}_{2} \mathrm{H}$ selectivity significantly.

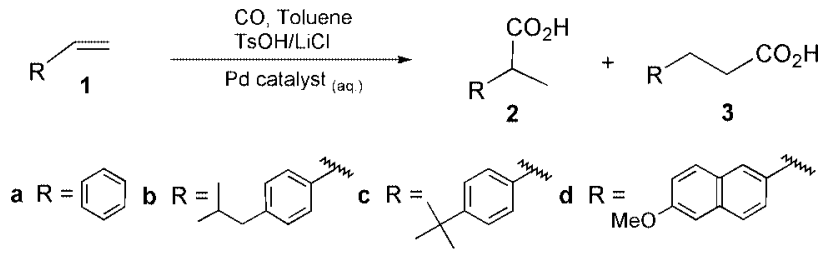

Scheme 2 Carbonylation of vinyl aromatics to 2-arylpropionic acids.

Table 1 Biphasic carbonylation of vinyl aromatics using the novel watersoluble Pd catalyst ${ }^{a}$

\begin{tabular}{ccccclc}
\hline & & & & & \multicolumn{2}{l}{ Selectivity $^{b}(\%)$} \\
\cline { 5 - 7 } Run & Substrate & Time/h & $\begin{array}{l}\text { Conver- } \\
\text { sion }(\%)\end{array}$ & TOF/h ${ }^{-1}$ & $\mathbf{2}$ & $\mathbf{3}$ \\
\hline $1^{c}$ & $1 \mathrm{a}$ & 1.42 & 94.5 & 302 & 92 & 7.2 \\
2 & $1 \mathrm{a}$ & 1.5 & 93 & 282 & 90.7 & 8.7 \\
$3^{d}$ & $1 \mathrm{a}$ & 4 & 78 & 89 & 45 & 54.6 \\
$4^{e}$ & $1 \mathrm{a}$ & 1.42 & 93 & 100 & 88 & 11.8 \\
$5^{f}$ & $1 \mathrm{a}$ & 1.5 & 91 & 550 & 95 & 4 \\
$6^{f}, g$ & $1 \mathrm{a}$ & 4 & 30 & 34 & 41.2 & 58 \\
$7^{h}$ & $1 \mathrm{a}$ & 2.5 & 76.5 & 139 & 76.5 & 23 \\
$8^{i}$ & $1 \mathrm{a}$ & 3.5 & 78 & 102 & 41 & 59 \\
$9^{f}$ & $1 \mathrm{~b}$ & 5 & 81 & 147 & 98 & 1.5 \\
$10^{f}$ & $1 \mathrm{c}$ & 3 & 90 & 273 & 96.6 & 2.8 \\
$11^{j}$ & $1 \mathrm{~d}$ & 12 & 45.5 & 10 & 93 & 6.5 \\
12 & $4 \mathrm{~b}$ & 5 & 20 & 18 & 98 & 2
\end{tabular}

a Conditions: $\mathrm{Pd}(0.0629 \mathrm{mmol})$, TPPTS/Pd $=3$, substrate $(28.8 \mathrm{mmol})$, TsOH (11.2 mmol), $\mathrm{LiCl}(11.2 \mathrm{mmol}), \mathrm{H}_{2} \mathrm{O}(6 \mathrm{ml})$, toluene $(15.5 \mathrm{ml}), P_{\mathrm{CO}}$ (54 bar), $T(388 \mathrm{~K}){ }^{b}$ Traces of bis $(\alpha$-methylbenzyl) ether was also detected. ${ }^{c}$ TPPTS $/ \mathrm{Pd}=2 .{ }^{d}$ TPPTS $/ \mathrm{Pd}=6 .{ }^{e}$ Substrate $(9.62 \mathrm{mmol})$. ${ }^{f}$ Substrate $(57.7 \mathrm{mmol}) .{ }^{g}$ Catalyst $=\mathrm{PdCl}_{2}-4$ TPPTS. ${ }^{h} \mathrm{HCl}$ instead of TsOH-LiCl. ${ }^{i}$ In the absence of LiCl. ${ }^{j}$ Substrate $(16.67 \mathrm{mmol})$. 
Reaction rates were highly dependent on substrate concentration as well as promoters. The TOF increased steadily with styrene concentration of up to $32 \%(57.7 \mathrm{mmol})$, presumably due to the increase in concentration of styrene in the aqueous catalytic phase in equilibrium with organic phase. The concentration of promoters $(\mathrm{TsOH}-\mathrm{LiCl})$ also showed a significant effect on the reaction rates; at lower concentrations the TOF and yields being extremely low. In the absence of $\mathrm{LiCl}$ the catalytic activity and selectivity decreased considerably (see run 8 , Table 1), suggesting a possible role of $\mathrm{LiCl}$ in the formation of phenylethyl chloride as the active carbonylation substrate. The formation of phenylethyl chloride was also confirmed by the analysis of intermediate organic phase samples. In addition, a small amount of phenylethyl alcohol was also detected in the intermediate samples, which may form by the acid catalyzed reversible hydration of the olefin. However, in the final reaction mixture only negligible amounts of the alcohol were detected.

Substituted vinyl aromatic compounds such as 4-isobutylstyrene $\left(\mathrm{TOF}=147 \mathrm{~h}^{-1}\right)$, and 4-tert-butylstyrene $(\mathrm{TOF}=273$ $\mathrm{h}^{-1}$ ) also gave good reaction rates though comparatively lower than that of styrene. 4-Isobutylstyrene gave high Ibuprofen selectivity of $98 \%$ while 6-methoxy-2-vinylnaphthalene gave 93\% selectivity to Naproxen under these conditions (TOF $=10$ $\mathrm{h}^{-1}$ ). Since secondary arylethanols can be dehydrated to vinyl aromatic compounds under acidic reaction conditions, carbonylation of 1-(4-isobutylphenyl)ethanol $(p \text {-IBPE })^{8}(\mathbf{4 b})$ was also studied. TOF up to $18 \mathrm{~h}^{-1}$ was achieved with an Ibuprofen selectivity of $98 \%$. Such a lower rate is expected considering the sluggish dehydration of IBPE to 4-isobutylstyrene under biphasic conditions.

In order to check whether the catalyst was reusable after the reaction, a few recycle experiments were carried out after phase separation. The recycle of catalyst after a reaction at $115{ }^{\circ} \mathrm{C}$ showed only very low catalytic activity $\left(\mathrm{TOF}=25 \mathrm{~h}^{-1}\right)$. However, recycle experiments under lower temperatures $\left(100-105^{\circ} \mathrm{C}\right)$ showed only negligible loss in catalytic activity. In all these cases analysis of Pd content in the organic phase after a reaction showed only $<0.05-0.1 \mathrm{ppm}$ of $\mathrm{Pd}$ indicating negligible leaching of Pd to the organic phase. The catalyst was efficiently reusable even at $115^{\circ} \mathrm{C}$ when fresh styrene was added to the reaction mixture under $\mathrm{CO}$ atmosphere. The analysis of the organic layer for Pd content after two such recycles also showed only $<0.1 \mathrm{ppm}$ of $\mathrm{Pd}$. These observations indicate that the catalyst is stable during an experiment and efficient recycle of the catalyst can be carried out under $\mathrm{CO}$. High conversions $(91 \%)$ achieved even at higher substrate concentrations (32\%, see run 5, Table 1) also support this argument. Traces of colloidal $\mathrm{Pd}$ formation were observed under certain conditions mainly at higher temperatures ( $>115$ $\left.{ }^{\circ} \mathrm{C}\right)$. Since the reaction is passing through the $\mathrm{Cl}$ derivative as the active carbonylation substrate, either of the two catalytic cycles involving $\mathrm{Pd}^{0} / \mathrm{Pd}^{\mathrm{II}}$ or $\mathrm{Pd}{ }^{\mathrm{II}} / \mathrm{Pd}^{\mathrm{IV}}$ seems to be possible. However, further studies on the nature of catalytic species under reaction conditions are essential to understand the actual reaction mechanism, which are currently in progress at our laboratory.

In conclusion, we have demonstrated a novel water-soluble $\mathrm{Pd}$ catalyst system, which is highly active for the regioselective carbonylation of vinyl aromatics to 2-arylpropionic acids under biphasic conditions and provides significant improvement over the current state of art for the biphasic carbonylation of vinyl aromatics.

S. J. and A. S. thank CSIR (Council of Scientific and Industrial Research), India for a research fellowship.

\section{Notes and references}

$\dagger$ I was dissolved in methyl ethyl ketone (MEK) $(10 \mathrm{ml})$ and shaken vigorously with 2 or 3 equiv. of TPPTS in $\mathrm{H}_{2} \mathrm{O}(6 \mathrm{ml})$. The yellow colour of the MEK layer disappears and the aqueous layer becomes yellow indicating the formation of II in water. For carbonylation reactions the aqueous layer was used after washing with pure MEK a few times (traces of MEK remain in the aqueous layer). All the solvents were degassed with $\mathrm{Ar}$ before use.

\$ The carbonylation reactions were carried out in a Parr Hastelloy C autoclave $(50 \mathrm{ml})$. In a typical reaction, the substrate $(28.8 \mathrm{mmol})$, catalyst $(0.0629 \mathrm{mmol})$ (prepared as above) in $6 \mathrm{ml}$ degassed water, $\mathrm{LiCl}-\mathrm{TsOH}$ (11.2 $\mathrm{mmol})$ and toluene $(15.5 \mathrm{ml})$ (degassed) were charged to the autoclave. The contents were flushed a few times with $\mathrm{N}_{2}$ followed by $\mathrm{CO}$ and heated to the desired temperature $\left(115^{\circ} \mathrm{C}\right)$. The autoclave was then pressurized with $\mathrm{CO}$ (54 bar) and the reaction was started by agitation (1100 $\mathrm{rpm}$ ) and was continued for the specified time. TOF $=$ Turnover Frequency $=$ number of moles of carbonylation product formed per mole of Pd per hour.

$\S$ The analysis of the liquid samples was carried out using a gas chromatograph (HP 5890) using a HP-FFAP capillary column.

II A yellow fine powder was precipitated as a suspension, which was allowed to settle, and the supernatant solution decanted. The precipitate was washed many times with $\mathrm{EtOH}$ and then with $\mathrm{Et}_{2} \mathrm{O}$ and dried under vacuum. All the solvents used were degassed with Ar prior to use.

\| Selected data for II: IR (KBr) $1636 \mathrm{~s}\left(v_{\mathrm{C}=\mathrm{O}}\right), 1397 \mathrm{~s}\left(v_{\mathrm{O}=\mathrm{C}-\mathrm{O}}\right), 524 \mathrm{~s}$ $\left(v_{\mathrm{Pd}-\mathrm{N}}\right) .{ }^{31} \mathrm{P}\left(\mathrm{D}_{2} \mathrm{O}, \mathrm{ppm}\right) \delta 35.31 \mathrm{~s}\left(\mathrm{~N}\right.$ trans to $\left.\mathrm{PPh}_{3}\right), \delta 36.13 \mathrm{w}(\mathrm{N}$ cis to $\left.\mathrm{PPh}_{3}\right) .{ }^{1} \mathrm{H}\left(\mathrm{D}_{2} \mathrm{O}, \mathrm{ppm}\right) \delta 2.25 \mathrm{~s}\left(3 \mathrm{H}\right.$, tolyl $\left.\mathrm{CH}_{3}\right), \delta 7.2-8 \mathrm{~m}$ ( $\mathrm{Ph}$ and pyridyl). (Found: C, 34.05; H, 3.28; N, 1.33; S, 12.32; P, 2.50. Calc. For $\mathrm{C}_{31} \mathrm{H}_{23} \mathrm{~N}$ $\mathrm{Na}_{3} \mathrm{O}_{14} \mathrm{PPdS}_{4} \cdot 6 \mathrm{H}_{2} \mathrm{O}$ : C, 34.598; H, 3.278; N, 1.301; S, 11.916; P, 2.878). Presence of $\mathrm{H}_{2} \mathrm{O}$ was also confirmed by ${ }^{1} \mathrm{H}$ NMR and IR.

1 (a) Aqueous phase organometallic catalysis: Concepts and applications, ed. B. Cornils and W. A. Herrmann, Wiley-VCH, Weinheim, 1998; (b) F. Bertoux, E. Monflier, Y. Castanet and A. Mortreux, J. Mol. Catal. A: Chem., 1999, 143, 11; (c) G.-J. ten Brink, I.W.C.E. Arends and R.A. Sheldon, Science, 2000, 287, 1636; (d) B. Zimmermann, J. Herwig and M. Beller, Angew. Chem., Int. Ed. Engl., 1999, 38, 2372.

2 (a) B. Cornils and E. Kuntz, J. Organomet. Chem., 1995, 502, 177; (b) Eur. Chem. News, 1995, Jan 15, 29.

3 (a) H. Alper and N. Hamel, J. Am. Chem. Soc., 1990, 112, 2803; (b) A. Seayad, S. Jayasree and R.V. Chaudhari, Org. Lett., 1999, 1, 459.

4 (a) V. Elango, M. A. Murphy, G. N. Mott, E. G. Zey, B. L. Smith and G. L. Moss, EP 400 892, 1990; (b) A. Seayad, S. Jayasree and R. V. Chaudhari, Catal. Lett., 1999, 61, 99; (c) H. Zhou, J. Cheng, S. Lu, H. Fu and H. Wang, J. Organomet. Chem., 1998, 556, 239; (d) S. Jayasree, A. Seayad and R. V. Chaudhari, Chem. Commun., 1999, 1067.

5 (a) G. Papadagianakis, G. Verspui, L. Matt and R.A. Sheldon, Catal. Lett., 1997, 47, 43; (b) S. Tilloy, E. Monflier, F. Bertoux, Y. Castanet and A. Mortreux, New J. Chem., 1997, 21, 529; (c) F. Bertoux, S. Tilloy, E. Monflier, Y. Castanet and A. Mortreux, J. Mol. Catal. A: Chem., 1999, 138, 53; $(d)$ F. Bertoux, E. Monflier, Y. Castanet and A. Mortreux, J. Mol. Catal. A: Chem.,1999, 143, 23.

6 M. S. Goedheijt, J. N. H. Reek, P. C. J. Kamer and P. W. N. M. van Leeuwen, Chem. Commun., 1998, 2431.

7 (a) R. V. Chaudhari, S. Jayasree and A. Seayad, Indian Patent Appl. 3697 DEL 98 March, 1999, US 6,069,253 Dt. 31-05-2000; (b) S. Jayasree, A. Seayad and R.V. Chaudhari, Org. Lett., 2000, 2, 203.

8 G. Papadogianakis, L. Maat and R. A. Sheldon, J. Chem. Tech. Biotech., 1997, 70, 83. 